\title{
The Paradigm Shift in Medical Imaging Education and Training in Europe
}

\author{
Rui Pedro Pereira de Almeida, Carlos Alberto da Silva, Bianca Isabel da Costa Vicente, António \\ Fernando Caldeira Lagem Abrantes, and Kevin Barros Azevedo
}

\begin{abstract}
The main goal of this literature review is to discuss the emerging trends, challenges and opportunities in the field of medical imaging education in Europe due to the Covid-19 pandemic scenario that forced the remodeling of the teaching and learning process. A bibliographic search was carried out in the main databases and from resources available in scientific and professional associations in Europe. Exclusion criteria included articles without contributions on distance learning or active learning. Education and training in medical imaging field had to readapt and the usual opportunities for medical imaging and radiotherapy (MIR) students to learn in person in the classroom, lab and clinical settings, had to be quickly transformed into distance learning opportunities. Thus, online education became a pedagogical shift from traditional method to the modern approach of teaching and learning from classroom to Zoom, from personal to virtual and from seminars to webinars, leading to the emergence of innovative teaching models. Moreover, student-centered strategies such as flipped classroom and game-based learning have been recently applied in health professions education with positive and very promising results. In conclusion, due to the pandemic crisis, MIR educators and students find themselves in the situation where they felt compelled to embrace the digital academic experience, allowing the progressive innovation of e-learning. In this context, game-based learning appears to be effective for improving knowledge, skills, attitudes and satisfaction and should be considered as a potential systematic tool in the field of medical imaging education. Therefore, preparedness of radiographers depends on the application of effective training and education methodologies that allows excellent clinical performance and maintaining high quality and safety standards, both through undergraduate course and continuous professional development.
\end{abstract}

Index Terms - Radiography education, medical imaging, game-based learning, flipped classroom, e-learning.

\section{INTRODUCTION}

In recent years, technological innovation has been a factor in changing the social paradigm and, above all, the prime driver of educational transformation [1]. Likewise, medical imaging professionals have also tried to develop and implement teaching and learning technologies, which offer greater convenience and allow the acquisition of knowledge and evidence for their clinical practice [2]-[4]. Even because

Manuscript received September 7, 2021; revised November 13, 2021

Rui Pedro Pereira de Almeida, Bianca Isabel Vicente, António Fernando Abrantes, and Kevin Barros Azevedo are with the University of Algarve, Portugal (e-mail: rpalmeida@ualg.pt, bivicente@ualg.pt, aabrantes@ualg.pt, kbazevedo@ualg.pt).

Carlos Alberto da Silva is with University of Évora, Portugal (e-mail: casilva@uevora.pt) the fact that some live in more rural or remote areas, often with less specialized healthcare, restricts their continued professional development opportunities [5].

Besides, professional ethics has a professional responsibility to maintain and enhance the knowledge, skills and attitudes in clinical practice, which is achieved through systematic participation in continuous training schemes according to the individual learning needs [6], [7]. But given the limited opportunities for face-to-face education, it is necessary to increasingly challenge traditional teaching methods and introduce e-learning technologies [7], [8].

All over the world, Covid-19 pandemic has forced educators to transform more quickly their lessons into online versions in a short period of time [9], [10]. A year passed since the pandemic began and, therefore, it is an opportune moment to seriously rethink, reformulate and redesign the educational system in such a demanding need of the current unprecedented situation [11]

Since the healthcare professional practices requires the most effective methods for teaching [12], the aim of this literature review is to discuss the emerging trends, challenges and opportunities in the field of medical imaging education in Europe, mainly due to the Covid-19 pandemic scenario that forced the remodeling of the teaching-learning process, which tends to be increasingly innovative and using new technologies.

\section{METHODS}

In this literature review, a bibliographic search was carried out in the main databases (Pubmed, ScienceDirect, LiLacs and Web of Science), complemented with gray literature and the use of resources available in scientific and professional associations and societies in this area of knowledge in Europe. Separate bibliographic searches were conducted in the different databases mentioned above and the search terms included "Radiology* OR Medical Imaging* OR Radiography" AND "Education* ("medical OR health professions" AND "e-learning OR active learning"). Exclusion criteria included articles not published in English, prior to 2013 and without contributions on distance learning or active learning.

As a literature review, the articles and documents included were evaluated in order to understand the trends in the teaching and learning of medical imaging education and its adaptation to the pandemic scenario, as well as to describe some future perspectives. Finally, the experiences of our imaging department are also referred to in the light of the existing literature. 


\section{MAIN FINDINGS}

\section{A. Emerging Trends and Current Challenges in Medical Imaging Education in Europe}

Medical Imaging is a dynamic, fast growing and highly technical field in healthcare, where the Radiographers and Radiologists are key elements who play an essential role across the diverse National Health Systems. However, the challenge they would have to face when an unknown virus emerged (COVID-19) would be unimaginable [13]. Due to its speed of propagation and pandemic incidence, there was a need to adapt practices and departments in order to minimize the risk of infection.

\section{1) The paradigm shift in medical imaging education}

With the official WHO declaration of Covid-19 pandemic on 11 March, several measures, guidelines and recommendations in medical imaging field have been constantly implemented and adapted in order to improve quality and safety in radiology departments [14]-[26]. Likewise, education and training in this field had to readapt and the usual opportunities for medical imaging and radiotherapy (MIR) students to learn in person in the classroom, lab and clinical settings, had to be quickly transformed into distance learning opportunities. Thus, online education became a pedagogical shift from traditional method to the modern approach of teaching-learning from classroom to Zoom, from personal to virtual and from seminars to webinars [11].

Unaware of the duration of the pandemic, there is a need to continue to provide education and training based on scientific evidence to those who will be in the frontline, allowing an adequate clinical practice. In addition, the lack of human resources has been identified as one of the main gaps in healthcare services [27], so newly graduated medical imaging professionals must be prepared to enter in the imaging departments at any time.

To guarantee the academic success of MIR students, universities can instill in their teaching-learning processes different tools and methodologies, in order to maximize the obtaining of knowledge and experiences by the future medical imaging professionals [28]. The use of such tools supported by highly qualified and experienced teachers and instructors is especially important in the early years of the undergraduate course and should serve as a foundation for clinical placements. Then, the hands-on clinical placement component of each program affords students the opportunity to work in both large and small medical facilities under the supervision of qualified staff, while utilizing their learned skills on actual patients [29]. This component is irreplaceable, because although it is possible to use virtual simulators of clinical teaching, they do not allow to obtain certain social relationship skills in the same dimension [30], [31]. Thus, the patient integration in the teaching-learning process is essential even in a pandemic context [32].

\section{2) The potential mixed education model}

Across the globe, academic institutions have been working hard to provide knowledge, skills and attitudes to MIR students, and conceptualizing learning processes towards vocational competence in a pandemic scenario [28], [30],
[33]-[36]. Due to the isolation and quarantine measures in most countries, it was necessary to implement digital tools for teaching (including clinical and practical simulation tools) which led to emergence of innovative teaching models [28].

For a long time, classroom learning was practically the only answer for traditional models of education. But in this pandemic context, we were forced to quickly include distance learning modalities, such as e-learning (Electronic Learning), b-learning (Blended Learning), m-learning (Mobile Learning) or u-learning (Ubiquitous Learning) [35]. There were changes in the way the teaching-learning process takes place, in the communication between professor and students, in the interaction with pedagogical and didactic materials, among many other transformations [28], [30], [34], [35]. However, clinical placement in hospital environment is irreplaceable, and so, it cannot be totally reproduceable through virtual learning. Therefore, a mixed teaching model could be beneficial in the current context.

Currently, there are several tools available that can be useful in this mixed model. In addition to the scientific databases (PubMed®, MEDLINE®, Scopus®, Web of Science ${ }^{\circledR}$, among others) that provide us with endless supporting documents, there are currently several tools available for free that can be used in MIR student learning, some of them to provide theoretical knowledge and others that interactively help in their consolidation, which are generally very well received by students. In fact, there is evidence that such tools can be used in different active learning strategies, improving student engagement and interaction [37]-[40]. Student-centered strategies such as team-based learning, case-based learning, flipped classroom and game-based learning have been recently applied in health professions education with positive and very promising results [39]-[45]. These strategies shift the focus of teaching from knowledge transmission to knowledge construction by students and encourage the use of tasks [37].

3) The experience from Medical Imaging and

Radiotherapy Department from Algarve University (Portugal)

From our experience, and similarly to the studies cited above, we have seen an improvement in MIR student's engagement and motivation applying student-centered strategies. In the current generation of true "digital natives", it can be achieved through gamification, using tools such as Kahoot [46]-[48]. Kahoot is a free game-based learning platform that brings engagement and fun to learn (any subject, in any language, on any device). The games can be based on multiple choice questions, true and false, and other types, can be played anywhere, in person or virtually, using any device with an internet connection, through a web browser or the Kahoot application [49]. In figure 1, we can see an example of several kahoots games created to monitor the theoretical knowledge acquired by MIR students from Algarve University.

Through the figure 2 we can see an example of a multiple-choice question used in a quiz held in a synchronized distance learning moment. The gameplay is simple: all students connect using a game PIN shown on the common screen and use a device (computer, mobile phone, 
etc.) to answer questions created by the professor. Each question can be assigned a specific response time and a specific score. Students who respond faster receive more points if they get it right. Points appear on the leaderboard after each question. And it is possible to adopt strategies in which students compete against each other individually, but it is also possible to adopt a teamwork strategy. After all MIR students have answered the question, or after the time set for each question has elapsed, the correct answer is presented.

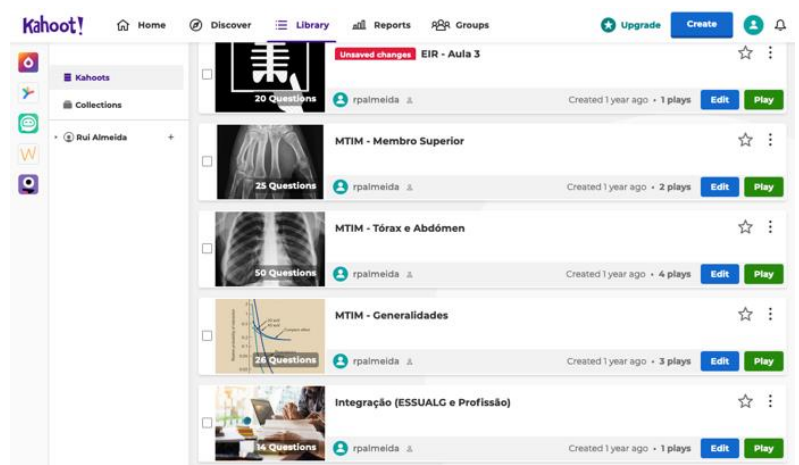

Fig. 1. Example of Kahoot desktop showing different games created to monitor the theoretical knowledge acquired by MIR students from Algarve University.

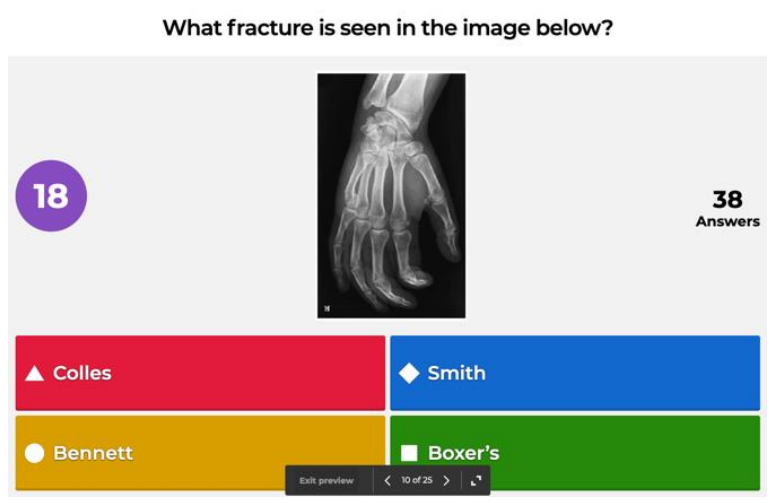

Fig. 2. Multiple choice question generated and made available to MIR students within the Kahoot environment, in the subject of methods and techniques in medical imaging.

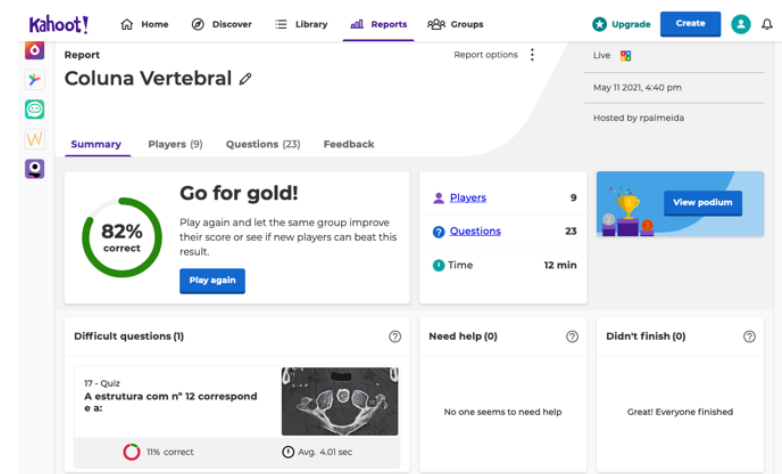

Fig. 3. Identification of MIR students to whom improvement proposals should be applied and identification of the main gaps.

Moreover, after finishing the quiz, a report is automatically prepared in order to monitor and follow the student's results. Based on these results, strategies are adopted for the identified gaps, aiming at a continuous improvement of the acquired knowledge. Through figure 3, we can see that only one issue was identified in which students had many difficulties, but none of the students was identified for targeted support in this quiz topic. There is also the possibility to export an excel file, which contains an overview of the results, the final scores for each student, as well as the individual results for each quiz question.

Because it is an interactive game, it is very well received by students. This tool allows to increase MIR student engagement, motivation, concentration and learning after using them repeatedly over time. The main factor in keeping students' attention after intense repeated use is mainly the competitive nature of Kahoot [47], [48], [50]. In addition to monitoring the theoretical knowledge and skills acquired, it also allows to obtain very useful information in order to carry out a more integrated and effective monitoring of MIR students, providing more favorable conditions for their academic success.

Therefore, this online tool allows the learners to demonstrate their capabilities in critical thinking and solving problems, which are the key benefits of shifting from traditional teaching to e-learning where the teacher is mainly a facilitator [51], [52].

Other public domain audience response resources are available, like Mentimeter and Poll Everywhere which are easy-to-use online tools that allows users to gather feedback and other data from their audience in various situations, with the ability to create custom polls and surveys, which can be answered [53], [54]. Therefore, these tools also allow to transform one-way presentations into a lively conversation with everyone in the meeting. The MIR students through the smartphones and devices that they use every day can submit live responses and watch them update directly on the shared screen. The professor can create and present multiple-choice questions, questions and answers, word clouds, ranking orders, curiosities and much more through the application on the Internet, the mobile application for the presenter or through the slide-ware integrations: PowerPoint, Google Slides or Keynote. It should be noted that both tools previously demonstrated can be used in a classroom environment or remotely through the platforms Zoom, Skype, Google Meets, among others.

In addition to these tools, other can be found and innovative approaches and modalities for medical imaging education are constantly appearing to improve teaching and learning and ultimately patient care and outcomes [44] Digital education is a demand, and the introduction of gamification strategies seems to be very useful.

In our context, Modular Object-Oriented Dynamic Learning Environment (Moodle) has also been a very useful resource. In fact, many international universities have integrated Moodle in their education and literature supports the use and importance of such tools [55]. Thus, this online learning platform should be integrated in medical imaging education to promote blended-learning in order to enhance the training of MIR students. Among its several features, we highlight the following: Forum (to promote discussions), Assignment (to collect, assess and provide feedback), Quiz (to assess learning), sharing folders and files, workshop, QR code for attendance, among many others [55], [56]. In terms of clinical placement, we have also innovated with the available resources, implementing electronic platforms for monitoring and evaluating students, and developing internship plans that respect the principle of equality, equity 
and proportionality of training opportunities in the different imaging modalities. The contact time in each modality is monitored using specific QR codes for each department. All planning is carried out considering an approach centered on the student's learning outcomes: the student at the center of the process.

For the preparation of teaching content, different public resources are also available, that meet the requirements of European Qualifications Framework level 6 and 7 (Graduate Diploma and Master's degree) in medical imaging curricular programs [57]-[59].

\section{4) Public domain medical imaging resources}

The ISRRT (International Society of Radiographers \& Radiological Technologists) provides a specific platform for e-learning, containing courses and materials especially useful in the topics identified below. In each of them, it is possible to see the learning objectives, support references and modules for assessing the knowledge acquired [60].

- Practical guidelines for radiographers during pandemic COVID-19

- International Covid-19 support for Radiographers and Radiologists

- Medical Imaging equipment procurement and equipment specifications

- Introduction to the Picture Archiving and Communication System

- Osteoporosis and DXA scanning

- Clinical Audit in Medical Imaging

- Digital Imaging: Issues in Quality and Radiation Safety

- Dose Reduction Techniques.

Also, the IAEA (International Atomic Energy Agency) has an e-learning area available free of charge after user registration. Here we can find, for example, a module on "Radiation Dose Management in CT" to address navigation into practical aspects of $\mathrm{CT}$ radiation dose and protocol creation [61]. Other topics of interest to the field of medical imaging, such as "Radiation Protection Basics", "Radiation Protection in fluoroscopy guided interventional procedures", "Tips \& Tricks: Radiation Protection in Radiology", "Quality Control and Dosimetry in Digital Imaging", "Image Guided Radiotherapy", "Quality and Safety in Radiotherapy", "SPECT/CT \& PET/CT”, among many others [62]. Most of these modules have feedback tools, as well as certificates of attendance in case of successful completion of the module.

Other websites such as Radiopaedia (contain 41381 imaging cases and 14917 articles) [63], MRI Master (for practical aspects of MRI) [64], Health Academy e-Learning Courses from World Health Organization [65], Virtual Pathology e-Learning training [66], Wikiradiography [67], Eurorad [68] and Education on Demand (from ESR European Society of Radiology) [69] are also good examples of electronic resources that can be used by MIR educators, students and medical professionals.

Finally, it is also worth mentioning the active role that ESR and EFRS (European Federation of Radiographer Society) has played in the educational and training context, mainly through webinars on several topics, which in 2020 were focused on "Radiation Protection in CT" and "Radiation
Protection in Radiotherapy" [70]. For this year of 2021, a new series of webinars focused on "Nuclear Medicine Radiation Protection" and Education \& Research" are also planned.

Given the above, it is unequivocal that there are different free resources that can be used and easily accessed to ensure that t-learning is successfully integrated into medical imaging education.

\section{B. Future Challenges}

Interactive Medical Imaging by implementing a Blended-Learning model with Augmented Reality and Game book, could be a possible way forward. From the experience of our university, there is already a successful "MILAGE Learn +" model for teaching mathematics, and promoting more interactive, active learning, adapted to the individual needs of students [71].

Thus, the potential development of an app as a tool to support MIR students in the autonomous resolution of exercises, through the incorporation of gamification characteristics, with different levels of exercise difficulty, to support students with greater learning difficulties and also include more advanced students. In addition, the inclusion of support videos, and self-assessment and peer review schemes aimed at stimulating the student's autonomous work, revisiting the contents for storing knowledge in long-term memory and identifying fundamental steps in solving problems, are solid evidence of the way forward [72]-[74].

One of the biggest challenges of a blended education model will certainly be to maintain high quality standards. Thus, the introduction of new technologies and tools must be systematically monitored, in order to accompany the students' learning process.

\section{CONCLUSION}

Due to the COVID-19 crisis, educators and students find themselves in the situation where they felt compelled to embrace the digital academic experience, allowing the progressive innovation of e-learning. Game-based learning appears to be effective for improving knowledge, skills, attitudes and satisfaction and should be considered as a potential systematic tool in the field of medical imaging education.

Adequate preparation of medical imaging professional to work independently and under pressure is a demand. Preparedness of these professionals depends on the application of effective training and education methodologies that allows excellent clinical performance and maintaining high quality and safety standards, both through undergraduate course and continuous professional development.

MIR students must rise to the challenges they face and, rigorously, quickly and effectively, make the necessary adaptations to their practices and their professional and educational context, with respect for international guidelines. This awareness will certainly be a step achieved in the course of these irreplaceable healthcare professionals. With the continuous improvement and development of this knowledge area, associated with the solutions available in the near future 
of artificial intelligence technology, it also leaves a promising field open for the education of MIR professionals.

Finally, this review highlights the need to design systematic studies and rigorous approaches in order to confirm the educational benefits of e-learning to support the traditional model, through a mixed approach to teaching and learning technologies.

\section{CONFLICT OF INTEREST}

The authors declare no conflict of interest.

\section{AUTHOR CONTRIBUTIONS}

All authors had contributed to the design and implementation of the research, to the analysis of the results and to the writing of the manuscript. In addition, all authors had approved the final version.

\section{ACKNOWLEDGMENT}

The authors would like to thank to the European Society of Radiology and to the European Federation of Radiographers Society for the opportunity to present the partial findings of this work at the European Radiology Congress 2021.

\section{REFERENCES}

[1] D. Garrison, E-Learning in the 21st Century: A Framework for Research and Practice, 2nd ed. New York: Routledge; 2011.

[2] C. Pape-Koehler, M. Immenroth, S. Sauerland et al., "Multimedia-based training on Internet platforms improves surgical performance: A randomized controlled trial," Surg Endosc., 2013, vol. 27, no. 5, pp. 1737-1747, doi:10.1007/s00464-012-2672-y.

[3] Z. Munn et al., "Evidence-based healthcare, knowledge translation, implementation science and radiography: What does it all mean?" Radiography, 2020, vol. 26, pp. S8-S13, doi:10.1016/j.radi.2020.05.008.

[4] A. Abrantes et al., "Evidence-based radiography: A new methodology or the systematisation of an old practice?" Radiography, 2020, vol. 26, no. 2, pp. 127-132, doi:10.1016/j.radi.2019.09.010.

[5] S. Maloney et al., "Health professional learner attitudes and use of digital learning resources," J Med Internet Res., 2013, vol. 15, no. 1, p. e7, doi:10.2196/jmir.2094.

[6] J. Nightingale, "Radiography education funding - Crisis or opportunity?" Radiography, 2016, vol. 22, no. 2, pp. 105-106, doi:10.1016/j.radi.2016.03.003.

[7] P. M. Sinclair et al., "The effectiveness of Internet-based e-learning on clinician behaviour and patient outcomes: A systematic review," Int J Nurs Stud., 2016, vol. 57, pp. 70-81, doi:10.1016/j.ijnurstu.2016.01.011.

[8] J. Lorimer and A. Hilliard, "Incorporating learning technologies into undergraduate radiography education," Radiography, 2009, vol. 15, no. 3, pp. 214-219, doi:10.1016/j.radi.2009.02.003.

[9] S. Ginkel et al., "Teachers' online teaching expectations and experiences during the Covid19-pandemic in the Netherlands," Eur J Teach Educ., 2020, vol. 43, no. 4, pp. 623-638, doi:10.1080/02619768.2020.1821185.

[10] H. A. Holzmann et al., "Combatendo o inimigo invisível: Fornecendo suporte e estrutura aos médicos residentes de radiologia durante a pandemia da COVID-19," Radiol Bras, 2020, vol. 53, no. 6, pp. 397-400.

[11] L. Mishra, T. Gupta, and A. Shree, "Online teaching-learning in higher education during lockdown period of COVID-19 pandemic," Int $J$ Educ Res Open, 2020.

[12] A. England and J. P. McNulty, "Inclusion of evidence and research in European radiography curricula," Radiography, 2020, vol. 26, pp. S45-S48, doi:10.1016/j.radi.2020.04.018.

[13] R. Almeida et al., "Pandemia COVID-19: Uma revisão da literatura," ROENTGEN-Revista Científica das Técnicas Radiológicas, 2020, vol. 1, 1, pp. 28-39, doi:10.46885/roentgen.v1i1.14.

[14] Y. Goh et al., Operational strategies to prevent coronavirus disease 2019 (COVID-19) spread in radiology: Experience from a Singapore radiology department after severe acute respiratory syndrome," J Am Coll Radiol, 2020, doi:10.1016/j.jacr.2020.03.027.

[15] J. M. Cots, J. Alós, M. Bárcena, and X. Boleda, "Infection control in the medical imaging department during the COVID-19 pandemic," $J$ Med Imaging Radiat Sci., 2020, pp. 1-3, doi:https://doi.org/10.1016/j.jmir.2020.03.005.

[16] A. M. Prabhakar et al., "Academic radiology departmental operational strategy related to the coronavirus disease 2019 (COVID-19) pandemic," J Am Coll Radiol., 2020, pp. 4-7, doi:10.1016/j.jacr.2020.04.004.

[17] H. Prosch et al., "COVID-19 patients and the radiology department advice from the European Society of Radiology (ESR) and the European Society of Thoracic Imaging (ESTI)," Eur Radiol., 2020, doi:10.1007/s00330-020-06865-y.

[18] J. Ding et al., "Prevention and control measures in radiology department for COVID-19," Eur Radiol., 2020 , doi:10.1007/s00330-020-06850-5.

[19] S. Kooraki et al., "Coronavirus (COVID-19) outbreak: What the department of radiology should know," J Am Coll Radiol., 2020, vol. 17, no. 4, pp. 447-451, doi:10.1016/j.jacr.2020.02.008.

[20] A. Sedaghat et al., "COVID-19 protection guidelines in outpatient medical imaging centers," Acad Radiol., 2020, doi:10.1016/j.acra.2020.04.019.

[21] A. Viswanath and P. Monga, "Working through the COVID-19 outbreak: Rapid review and recommendations for MSK and allied heath personnel," J Clin Orthop Trauma., 2020, pp. 500-503, doi:https://doi.org/10.1016/j.jcot.2020.03.014.

[22] S. Mohakud et al., "COVID-19 preparedness for portable X-rays in an Indian hospital - Safety of the radiographers, the frontline warriors," Radiography, 2020, pp. 10-11.

[23] I. Y. Y. Tsou et al., "Planning and coordination of the radiological response to the coronavirus disease 2019 (COVID-19) pandemic: the Singapore experience," Clin Radiol., 2020, vol. 75, no. 6, pp. 415-422, doi:10.1016/j.crad.2020.03.028.

[24] Y. Zhao et al., "Radiology department strategies to protect radiologic technologists against COVID19: Experience from Wuhan," Eur J Radiol., 2020, doi:10.1016/j.ejrad.2020.108996.

[25] M. Zanardo et al., "Management of patients with suspected or confirmed COVID-19, in the radiology department," Radiography, 2020, doi:10.1016/j.radi.2020.04.010.

[26] J. Qu et al., "Infection control for ct equipment and radiographers' personal protection during the coronavirus disease (COVID-19) outbreak in China," AJR Am J Roentgenol., 2020, pp. 1-5, doi:10.2214/AJR.20.23112.

[27] (2021). Renovação Estado Emergência - 28 janeiro - Covid 19 estamos ON. [Online]. Available: https://covid19estamoson.gov.pt/renovacao-estado-emergencia-28-jan eiro/

[28] L .A. Rainford et al., "The impact of COVID-19 upon student radiographers and clinical training," Radiography, 2020, doi:10.1016/j.radi.2020.10.015.

[29] E. Hyde, "A critical evaluation of student radiographers' experience of the transition from the classroom to their first clinical placement," Radiography, 2015, vol. 21, no. 3, pp. 242-247, doi:10.1016/j.radi.2014.12.005.

[30] M. Al-Balas et al., "Distance learning in clinical medical education amid COVID-19 pandemic in Jordan: Current situation, challenges, and perspectives," BMC Med Educ., 2020, vol. 20, no. 1, p. 341, doi:10.1186/s12909-020-02257-4.

[31] S. J. Ketterer et al., "Simulated versus traditional therapeutic radiography placements: A randomised controlled trial," Radiography, 2020, vol. 26, no. 2, pp. 140-146, doi:10.1016/j.radi.2019.10.005.

[32] A. I. Alhaqwi and W. S. Taha, "Promoting excellence in teaching and learning in clinical education," J Taibah Univ Med Sci., 2015, vol. 10, no. 1, pp. 97-101, doi:10.1016/j.jtumed.2015.02.005.

[33] R. J. Wilcha, "Effectiveness of virtual medical teaching during the COVID-19 crisis: Systematic review," JMIR Med Educ., 2020, vol. 6, no. 2, p. e20963, doi:10.2196/20963.

[34] S. Dost et al., "Perceptions of medical students towards online teaching during the COVID-19 pandemic: A national cross-sectional survey of 2721 UK medical students," BMJ Open, 2020, vol. 10, no. 11, e042378, doi:10.1136/bmjopen-2020-042378.

[35] R. Olum et al., "Medical education and e-learning during COVID-19 pandemic: Awareness, attitudes, preferences, and barriers among undergraduate medicine and nursing students at Makerere University, Uganda," J Med Educ Curric Dev., 2020, vol. 7, 238212052097321, doi:10.1177/2382120520973212. 
[36] S. O. Cheng and A. Liu, "Using online medical education beyond the COVID-19 pandemic - A commentary on "The coronavirus (COVID-19) pandemic: Adaptations in medical education," Int J Surg., 2020, vol. 84, pp. 159-160, doi:10.1016/j.ijsu.2020.11.010.

[37] K. Singh et al., "Teaching anatomy using an active and engaging learning strategy," BMC Med Educ., 2019, vol. 19, no. 1, doi:10.1186/s12909-019-1590-2.

[38] W. Sumanasekera et al., "Evaluation of multiple active learning strategies in a pharmacology course," Curr Pharm Teach Learn, 2020, vol. 12, no. 1, pp. 88-94, doi:10.1016/j.cptl.2019.10.016.

[39] Y. Alruthia et al., "The use of active learning strategies in healthcare colleges in the Middle East," BMC Med Educ., 2019, vol. 19, no. 1, doi:10.1186/s12909-019-1580-4.

[40] A. F. Silva, É possível alinhar o ensino da radiologia na graduação em medicina, pós-graduação e educação médica continuada?" Radiol Bras. 2018, vol. 51, no. 6, pp. 407-407.

[41] S. Wu et al., "Existing contradictions and suggestions: Flipped classroom in radiology courses of musculoskeletal disease under Chinese medical educational mode from medical imaging student perspective," BMC Med Educ., 2020, vol. 20, no. 1 , doi:10.1186/s12909-020-1991-2.

[42] K. F. Hew and C. K. Lo, "Flipped classroom improves student learning in health professions education: A meta-analysis," BMC Med Educ., 2018, vol. 18, no. 1, doi:10.1186/s12909-018-1144-z.

[43] A. Y. Utomo et al., "Gamified e-learning model based on community of inquiry," in Proc. ICACSIS 2014: 2014 International Conference on Advanced Computer Science and Information Systems, Institute of Electrical and Electronics Engineers Inc., 2014, pp. 474-480, doi:10.1109/ICACSIS.2014.7065830.

[44] C. Dichev and D. Dicheva, "Gamifying education: What is known, what is believed and what remains uncertain: a critical review," Int $J$ Educ Technol High Educ., 2017, vol. 14, no. 1, p. 9, doi:10.1186/s41239-017-0042-5.

[45] C. M. Barrio et al., "Can gamification improve the benefits of student response systems in learning? An experimental study," IEEE Trans Emerg Top Comput., 2016, vol. 4, no. 3, pp. 429-438, doi:10.1109/TETC.2015.2497459.

[46] M. A. Royse and S. E. Newton, "How gaming is used as an innovative strategy for nursing education," Nurs Educ Perspect, 2007, vol. 28, no. 5, $\quad$ pp. 263-267, doi:10.1043/1536-5026(2007)28[263:HGIUAA]2.0.CO;2.

[47] D. Neureiter et al., "Feasibility of Kahoot! as a real-time assessment tool in (histo-)pathology classroom teaching," Adv Med Educ Pract., 2020, vol. 11, pp. 695-705, doi:10.2147/AMEP.S264821.

[48] C. L. Kuo and Y. H. Chuang, "Kahoot: Applications and effects in education," $J$ Nurs., 2018, vol. 65, no. 6, pp. 13-19, doi:10.6224/JN.201812 65(6).03

[49] About Kahoot! | Company History \& Key Facts, 2021.

[50] K. Singh et al., "Flipped classroom: A concept for engaging medical students in learning," INDIAN Pediatr., 2018, p. 507.

[51] D. A. Cook et al., "Internet-based learning in the health professions: A meta-analysis," JAMA - J Am Med Assoc., 2008, vol. 300, no. 10, pp. 1181-1196, doi:10.1001/jama.300.10.1181

[52] A. Elzain et al., "Experience of e-learning and online assessment during the COVID-19 pandemic at the College of Medicine, Qassim University," J Taibah Univ Med Sci., 2020, vol. 15, no. 6, pp. 456-462, doi:10.1016/j.jtumed.2020.09.005.

[53] Activities | Poll Everywhere, 2021.

[54] Interactive presentation software - Mentimeter. [Online]. Available: https://www.mentimeter.com/

[55] A. Memon and F. Rathore, "Moodle and online learning in pakistani medical universities: An opportunity worth exploring in higher education and research," J Park Med Assoc., 2018, vol. 68, no. 7, pp. 1076-1078.

[56] Moodle Tool Guide. [Online]. Available: https://moodletoolguide.net/en/

[57] European Federation of Radiographers Societies, EFRS Statement on Radiography Education, 2019.

[58] L. Žunic, "The legal framework for academic professional development for radiographers in higher education," Med Law Soc., 2019, vol. 12,no. 1, pp. 65-84, doi:10.18690/ml\&s.12.1.65-84.2019.

[59] A. Wareing et al., "Continuing professional development (CPD) in radiography: A collaborative European meta-ethnography literature review," Radiography, 2017, vol. 23, pp. S58-S63, doi:10.1016/j.radi.2017.05.016.

[60] International Society of Radiographers \& Radiological Technologists. ISRRT. [Online]. Available: https://www.isrrt.org/
[61] Radiation Dose Management in CT. [Online]. Available: http://ns-files.iaea.org/training/rpop/ct-e-learning/story_html5.html

[62] International Atomic Energy Agency. OPEN-LMS: All courses. [Online]. https://elearning.iaea.org/m2/course/index.php?categoryid=42

[63] Radiopaedia.org, the wiki-based collaborative Radiology resource. [Online]. Available: https://radiopaedia.org/. Accessed February 22, 2021.

[64] MRI protocols, MRI planning, MRI techniques and anatomy. [Online]. Available: https://mrimaster.com/. Accessed February 22, 2021.

[65] WHO | Health Academy eLearning Courses. (2017). [Online] Available: http://www.who.int/healthacademy/courses/en/

[66] Virtual Pathology eLearning. [Online]. Available: https://elearning.virtualpathology.leeds.ac.uk/. Accessed February 22, 2021.

[67] CT Anatomy - Head - wikiRadiography. [Online]. Available: http://www.wikiradiography.net/page/CT_Anatomy_-_Head

[68] Homepage | Eurorad. [Online]. Available: https://www.eurorad.org/

[69] European Society of Radiology. Education on Demand. [Online] Available: https://learn-myesr.talentlms.com/. Accessed February 22, 2021.

[70] European Federation of Radiographer Society. EFRS. [Online]. Available: https://efrs.eu/webinar-recordings. Accessed February 1, 2021.

[71] Aprender+ - MILAGE. [Online]. Available: https://milage.ualg.pt/?page_id=1176

[72] A. F. Oliveira et al., "O aprendizado sobre a tecnologia no diagnóstico por imagem," Radiol Bras, 2014.

[73] T. R .Dias, J. D. Junior, and N. Abdala, "Curva de aprendizado de residentes em radiologia durante treinamento em punção de articulações facetárias guiada por fluoroscopia," Radiol Bras, 2017.

[74] M. Zanon et al., "Facebook como uma ferramenta para impulsionar a educação em radiologia: expandindo-se de uma comunidade local de estudantes de medicina para a América do Sul,” Radiol Bras, 2018.

Copyright $(2022$ by the authors. This is an open access article distributed under the Creative Commons Attribution License which permits unrestricted use, distribution, and reproduction in any medium, provided the original work is properly cited (CC BY 4.0).

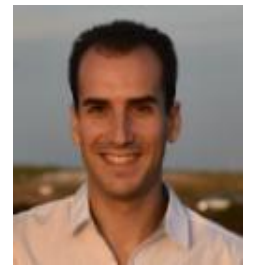

Rui Pedro Pereira de Almeida is an adjunct professor of Medical Imaging and Radiotherapy Department, a division under the School of Health in University of Algarve, a public university in Portugal $\mathrm{He}$ is the vice-president of the Portuguese Association of Medical Imaging and Radiotherapy (APIMR). Also, he is researcher at CICS.NOVA.UÉvora (Interdisciplinary Center of Social Sciences) from the University of Évora, Portugal, and at Center for Research and Development in Health (CES), University of Algarve, Portugal. $\mathrm{He}$ has the BSc of honours in radiology (2009), the MSc in quality management in healthcare services (2015) and the $\mathrm{PhD}$ in health sciences (2020).

Carlos Alberto da Silva is a full professor and the head of the Department of Medical and Health Sciences, a division under the School of Health and Human Development in the University of Évora, a public university in Portugal. He is the coordinator of the research center CICS.NOVA.UÉvora (Interdisciplinary Center of Social Sciences) from the University of Évora, Portugal, He has the habilitation degree (Aggregation) in Sociology of Organization, $\mathrm{PhD}$ and Master degree in Sociology, and Bachelor degree in Radiology. Its main research interests were: prospective studies; health technology assessment; mixed methods for planning and evaluation of health-related programs and projects.

Bianca Isabel da Costa Vicente is an assistant professor of Medical Imaging and Radiotherapy Department, a division under the School of Health in University of Algarve, a public university in Portugal. She has the $\mathrm{BSc}$ of honours in medical imaging and radiotherapy, post-graduation and advanced training in health technology management and assessment, and she is currently a doctoral student in health sciences.

António Fernando Caldeira Lagem Abrantes is the head of Imaging and Radiotherapy Department, a division under the School of Health in University of Algarve, a public university in Portugal. Also, he is integrated researcher at CICS.NOVA.UÉvora (Interdisciplinary Center of Social Sciences) from the University of Évora, Portugal, and at Center for Research and Development in Health (CES), University of Algarve, Portugal. Also, he 
is a member of the Board of the Technological Assessment Observatory. He has the BSc of honours in radiology, the MSc in socio-organizational intervention in health and the $\mathrm{PhD}$ in sociology.

Kevin Barros Azevedo is an adjunct professor of Medical Imaging and Radiotherapy Department, a division under the School of Health in University of Algarve, a public university in Portugal. He is the chairman of the assembly of the Portuguese Association of Medical Imaging and
Radiotherapy (APIMR). Also, he is researcher at CICS.NOVA.UEvora (Interdisciplinary Center of Social Sciences) from the University of Évora Portugal, and at Center for Research and Development in Health (CES), University of Algarve, Portugal. He has the BSc of honours in radiology, the $\mathrm{MSc}$ in medicine and the PhD in health sciences. 